\title{
A Comparative Evaluation of Marginal Leakage of Different Restorative Materials in Deciduous Molars: An in vitro Study
}

\author{
Gunjan Yadav, Usha Rehani, Vivek Rana
}

\begin{abstract}
Context: Microleakage around dental restorative materials is a major problem in clinical dentistry. Inspite of many new restorative materials available in the market very few actually bond to the tooth surface.
\end{abstract}

Aims: The aims of this study were: (1) To evaluate and compare the marginal leakage of newer restorative materials viz colored compomer, ormocer, giomer and RMGIC in class I restoration of deciduous molars. (2) To compare the microleakage scores between the groups of: Colored compomer and ormocer, giomer and $\mathrm{RMGIC}$, ormocer with giomer and RMGIC, giomer with RMGIC.

Materials and methods: A total of 40 primary molars were randomly divided into four groups of 10 each. Class I cavities were prepared and the cavities were restored with colored compomer (Group A), Ormocer (Group B), Giomer (Group C) and RMGIC (Group D). The teeth were thermocycled and subjected to $0.5 \%$ basic fuchsin dye penetration followed by sectioning. The cut sections were evaluated under a stereomicroscope and the data was subjected to statistical analysis.

Statistical analysis used: Mann-Whitney U test and Student t-test.

Results: No significant difference was observed when colored compomer was compared to ormocer, giomer and RMGIC. Ormocer showed significantly lower microleakage when compared to giomer. However, no significant difference was observed when ormocer was compared to RMGIC. No significant difference between giomer and RMGIC was found.

Conclusion: Ormocer has proven to be an excellent restorative material as it showed least microleakage followed by colored compomer, giomer and RMGIC in increasing order.

Keywords: Colored compomer, Ormocer, Giomer, RMGIC and microleakage.

How to cite this article: Yadav G, Rehani U, Rana V. A Comparative Evaluation of Marginal Leakage of Different Restorative Materials in Deciduous Molars: An in vitro Study . Int J Clin Pediatr Dent 2012;5(2):101-107.

Source of support: Nil

Conflict of interest: None declared

\section{INTRODUCTION}

The goal of restorative dentistry is undoubtedly to restore the tooth to its form and function. One of the requisites is to adapt well and seal the cavity walls for the longevity of the restoration. There has always been a keen interest in the adaptation of dental restorative materials to the walls of the cavity and the retentive ability of a material to seal the cavity against ingress of oral fluids and microorganisms. ${ }^{1}$ Microleakage around dental restorative materials is a major problem in clinical dentistry. It may be defined as 'the clinically undetectable passage of bacteria, fluids, molecules or ions between a cavity wall and the restorative materials applied to it'. ${ }^{2}$ This seepage can cause hypersensitivity of restored teeth, tooth discoloration, recurrent caries, pulpal injury and accelerated deterioration of some restorative materials. ${ }^{1}$

Inspite of many new materials in the market like GIC, composite, compomers, giomers and now ceromers and ormocers very few materials actually bond to the tooth surface. Dimensional changes and lack of adaptation of the restoration to cavity walls can lead to marginal leakage with fluid and molecular movement and the ingress of bacteria or bacterial nutrients. ${ }^{3}$

Thus, the procurement of a perfect seal on the restoration tooth interface is one of the prime goals of restorative dentistry in order to prevent penetration of microorganisms and other contaminants. Thus, it is evident that poor marginal seal impacts a major drawback in longevity of restoration.

Fluoride releasing and chemical bonding properties of glass ionomer cements are well known. However, poor physical properties, such as tendency to undergo surface crazing, low fracture resistance and esthetics limit its use. ${ }^{1}$ To overcome this resin-modified glass ionomers (RMGIs) were developed. The advantages of RMGIs are that it is biocompatible and fluoride release is similar to those of conventional GI, improved physical properties, especially with regard to tensile strength and abrasion resistance, better wear resistance, good adhesion to enamel and dentin and satisfactory esthetics. ${ }^{4}$

Because of perceived inadequacies in the ease of use of composites as several clinical steps are required to obtain a good interfacial bond, compomers were introduced. Colored

Note: Ormocer has proven to be an excellent restorative material as it showed least microleakage followed by colored compomer, giomer and RMGIC in increasing order. As giomer is a new material and not much of studies have been done on it so more work is needed to be done to have a better opinion of this new material. 
compomers have been introduced in the market in various attractive colors with glitter effect. It offers a perfect solution for nervous, frightened and impatient children. It shows excellent physical properties and high fluoride release for prevention of secondary caries. ${ }^{5,6}$

The research of finding a filling material which was superior to contemporary composite has led to the evolution of a new material called ormocers. Ormocer-the acronym of organically modified ceramic is a new material for all filling indications in the anterior and posterior area which serve as an optimum and up to date replacement for amalgam, composites and compomers. ${ }^{7-9}$

In the continuing quest for improved glass ionomer like restorations manufacturers have introduced a new class of materials called giomers. It has properties of both glass ionomers (fluoride release and fluoride recharge) and resin composites-(excellent esthetics, easy polishability and biocompatibility).

Thus, it is evident from the literature and long experiences of dental professionals that poor marginal seal imparts a major drawback in longevity of the restoration. So, the present in vitro study is envisaged to compare the marginal leakage of colored compomer, ormocer, giomer and resin-modified glass ionomer cement in class I restoration of deciduous molars.

\section{MATERIALS AND METHODS}

The present in vitro study was carried out in the Department of Pedodontics and Preventive Dentistry, Subharti Dental College, Meerut in collaboration with Department of Endocrinology, Central Drug Research Institute, Lucknow and Birbal Sahni Institute of Paleobotany, Lucknow to evaluate and compare the marginal leakage of various restorative materials in deciduous molars.

A total of 40 noncarious primary molars which were extracted for the reason of overretention were selected for the study. Surface debridement of all the teeth was done with hand instruments and the teeth were stored in normal saline at room temperature till further use. The teeth were randomly divided into four groups of 10 teeth each.

Standard class I cavities were prepared on all the 40 teeth using round bur, straight bur and inverted cone bur with a low speed contra angle hand piece using constant water-spray. The depth of the cavity was standardized to 1 to $2 \mathrm{~mm}$ with no mechanical retention form. Prepared cavities were then thoroughly cleaned with water and gently dried before the placement of the restoration.

In each group the cavity was restored with its respective restorative material according to the manufacturer's instructions (Figs 1 and 2).

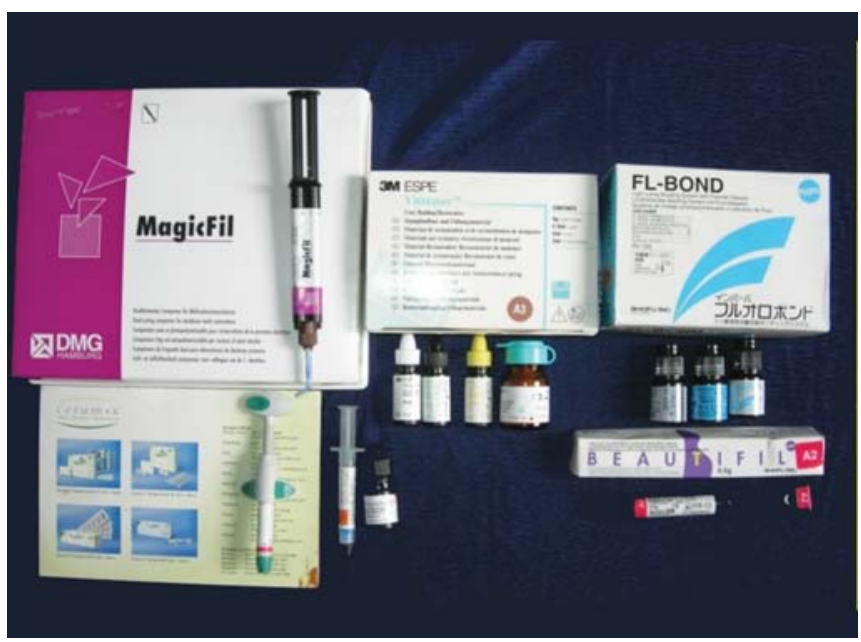

Fig. 1: Restorative materials

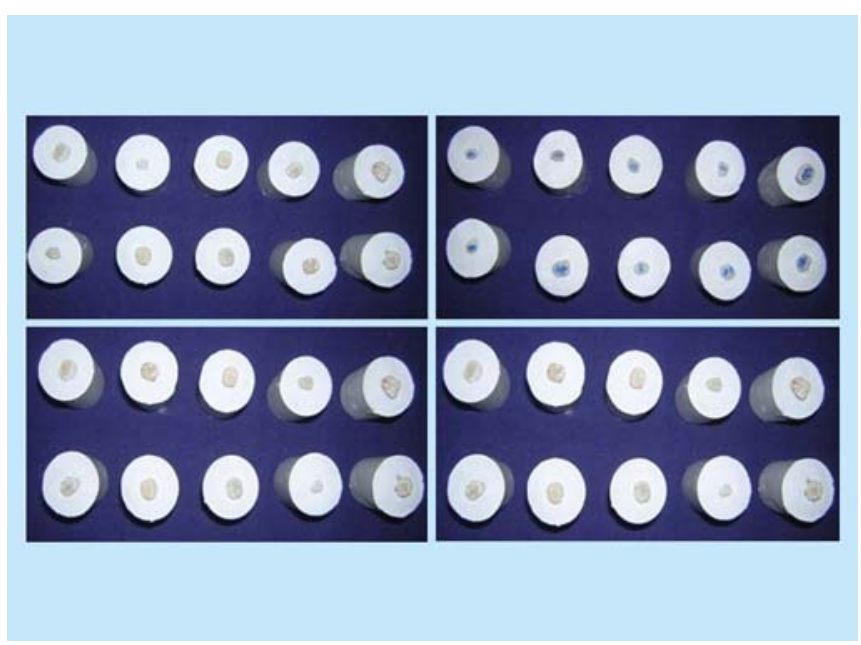

Fig. 2: Samples restored with different materials

\begin{tabular}{|c|c|c|c|}
\hline Groups & $\begin{array}{l}\text { Restorative } \\
\text { material }\end{array}$ & $\begin{array}{l}\text { Commercial } \\
\text { name }\end{array}$ & $\begin{array}{l}\text { Manufacturing } \\
\text { company }\end{array}$ \\
\hline Group A & $\begin{array}{l}\text { Colored } \\
\text { compomer }\end{array}$ & MagicFil & $\begin{array}{l}\text { Zenith/DMG, } \\
\text { Englewood,NJ }\end{array}$ \\
\hline Group B & Ormocer & Ceram X & Dentsply \\
\hline Group C & Giomer & Beautifil & $\begin{array}{l}\text { Shofu Inc } \\
\text { Kyoto Japan }\end{array}$ \\
\hline Group D & $\begin{array}{l}\text { Resin } \\
\text { modified } \\
\text { glass ionomer } \\
\text { cement }\end{array}$ & Vitremer & $\begin{array}{l}\text { 3M Dental } \\
\text { product, USA }\end{array}$ \\
\hline
\end{tabular}

After 24 hours of storage in distilled water, teeth were then subjected to thermocycling for 200 cycles at a temperature of $4{ }^{\circ} \mathrm{C} \pm 2^{\circ} \mathrm{C}$ and $50^{\circ} \mathrm{C} \pm 2^{\circ} \mathrm{C}$ with dwell time of 10 seconds.

The specimens were then prepared for dye exposure. Each tooth was covered with nail polish except an area approximately within $1 \mathrm{~mm}$ of periphery of the restoration. The apices of the teeth were occluded with modeling wax 
to prevent leakage through root apices. The teeth were then immersed in $0.5 \%$ basic fuchsin dye for 24 hours at room temperature (Fig. 3). After removal from the dye, samples were thoroughly cleaned and rinsed under tap water until all the dye was removed from the surface. Then the samples were mounted in self-curing acrylic blocks (Fig. 4) and sectioned buccolingually through the center of the restoration with a low-speed diamond saw (Fig. 5).

The teeth were then examined under stereomicroscope (16X magnification) to measure the depth of the dye penetration at the two surfaces of the cavity and the score which was higher was given as a score to the particular tooth (Fig. 6). All the scoring was carried out by a single person and the scoring criteria used for the study was as follows:

The following criteria were used to score dye penetration. ${ }^{10}$

\begin{tabular}{ll}
\hline 0 & No dye penetration (Fig. 7) \\
1 & $\begin{array}{l}\text { Dye penetration between the restoration and } \\
\text { the tooth into enamel only (Fig. 8) }\end{array}$ \\
2 & $\begin{array}{l}\text { Dye penetration between the restoration and } \\
\text { the tooth into enamel and dentin (Fig. 9) }\end{array}$ \\
3 & $\begin{array}{l}\text { Dye penetration between the restoration and } \\
\text { the tooth into the pulp chamber (Fig. 10) }\end{array}$ \\
\hline
\end{tabular}

The score was tabulated, interpreted and the resultant findings were statistically analyzed.

\section{RESULTS}

All the 40 samples were evaluated; score of dye penetration, mean and standard deviation were calculated. MannWhitney U-test (Table 2) and Student t-test were used for the comparison between the groups.

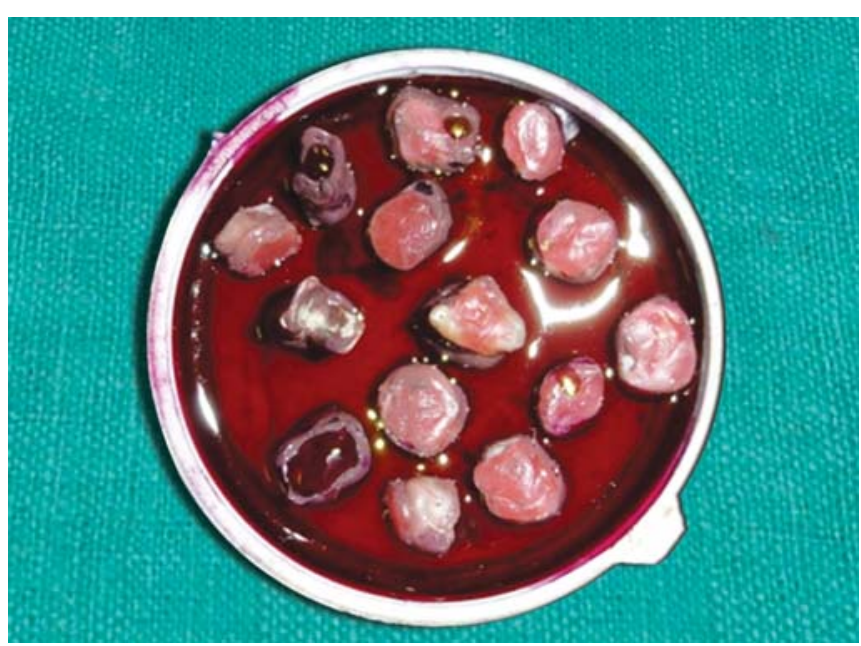

Fig. 3: Samples following nail varnish application and dye penetration

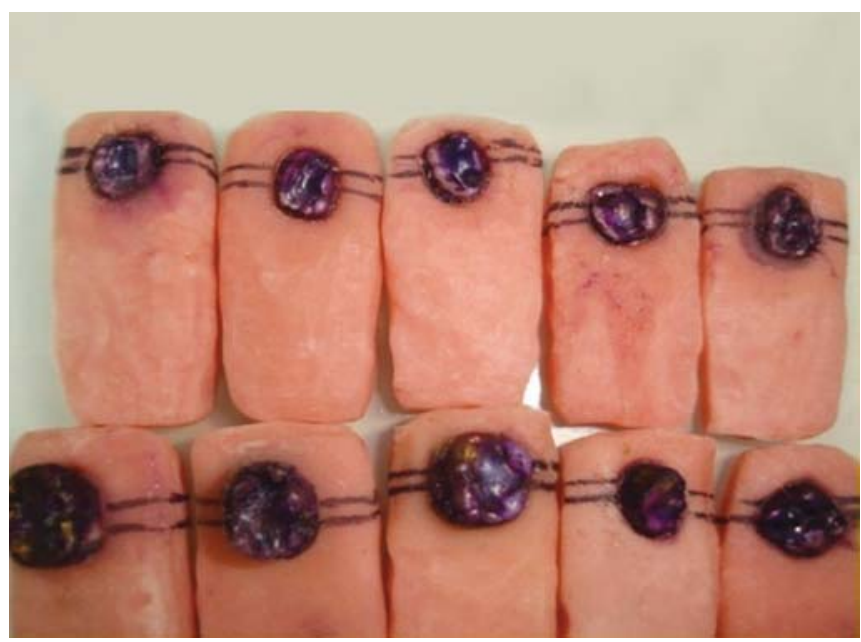

Fig. 4: Sample preparation for section cutting

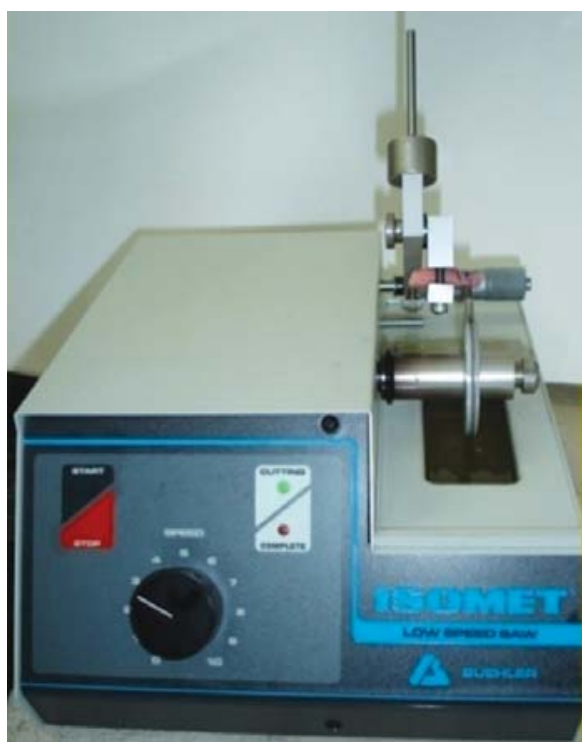

Fig. 5: Low speed diamond saw

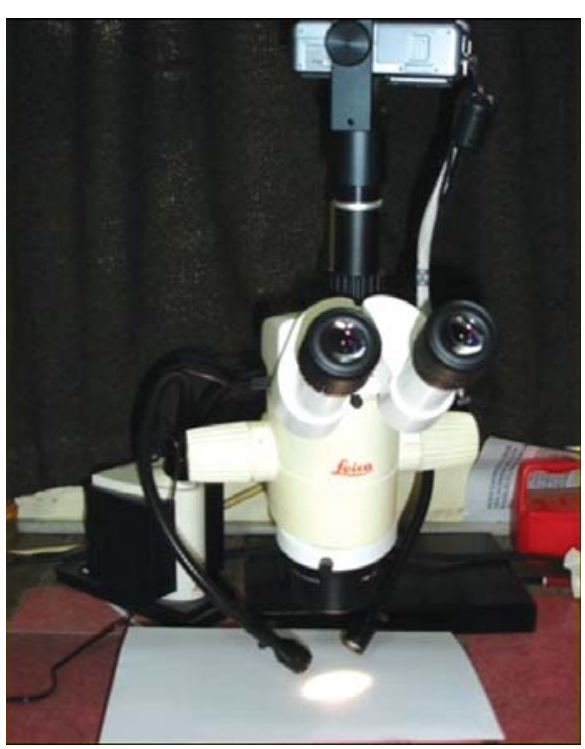

Fig. 6: Stereomicroscope used to check microleakage in the specimen 


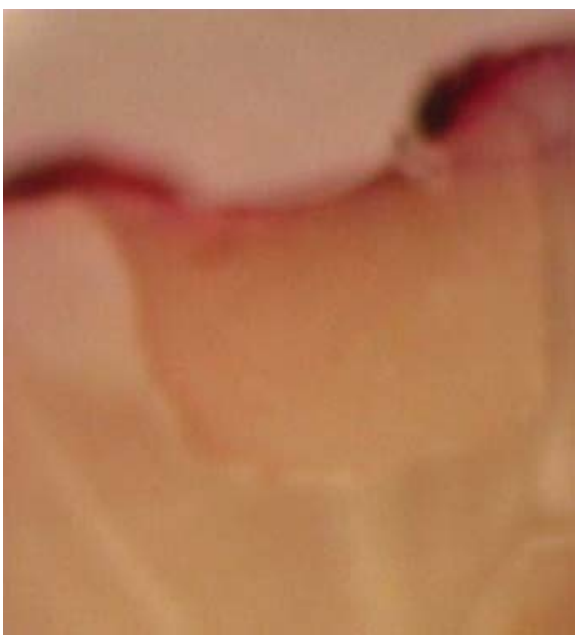

Fig. 7: No dye penetration (score 0) in Ormocer

Table 1 and Graph 1 show that out of the 10 teeth filled with colored compomer eight teeth showed no dye penetration at all, one tooth showed dye penetration up to enamel, i.e. score 1 , and one tooth showed dye penetration into the pulp chamber (score 3).

Of the 10 teeth filled with ormocer, nine teeth showed no dye penetration, and one tooth showed penetration with score 1.

Of the 10 teeth filled with giomer, three teeth showed no dye penetration, five showed score of one, another two showed microleakage with score 3 .

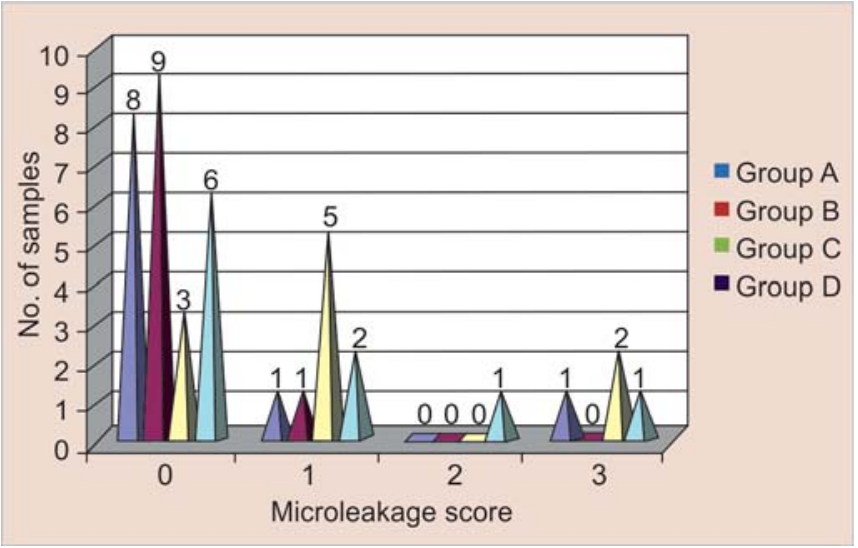

Graph 1: Descriptive statistics of the comparison of microleakage scores among various restorative materials
Of the 10 teeth filled with RMGIC, six teeth showed no dye penetration, two showed score of 1 , another one tooth showed microleakage with score 2 and one tooth showed microleakage upto the level of pulp chamber, i.e. score 3.

Ormocer showed the least microleakage with mean score and standard deviation of $0.1 \pm 0.3162$ as compared to colored compomer with mean score and standard deviation of $0.4 \pm 0.9661$ and RMGIC with mean score and standard deviation of $1.1 \pm 1.1005$.

No significant difference was observed when colored compomer was compared to ormocer, giomer and RMGIC.

Ormocer showed significantly lower microleakage ( $\mathrm{p}<0.05)$ when compared to giomer. However, no significant difference was observed when ormocer was compared to RMGIC.

There was no significant difference when giomer was compared to RMGIC.

\section{DISCUSSION}

A major goal in restorative dentistry is the control of marginal leakage which may occur because of dimensional changes or lack of adaptation of the restorative materials to the cavity preparation. These interfacial gaps may lead to recurrent caries and pulpal pathosis. ${ }^{11}$

It is apparent that microleakage around restorations is a series of phenomena and not a single entity. Although ionic charge and chemical reactivity of diffusing fluids have a part in marginal leakage, the physical and chemical nature of restorative materials and the clinical skills of the operator play equally important roles. It must be recognized that application of the restorative materials in vivo is more difficult than their application in vitro on extracted teeth. An adequate seal in vivo is unquestionably and undoubtedly difficult to obtain.

In the present study, microleakage was seen to some extent with almost all the dental restorative materials. This has been suggested earlier by Gladys S et al $(2001)^{12}$ that microleakage can be expected with all the dental restorative

\begin{tabular}{|c|c|c|c|c|c|c|c|c|}
\hline \multirow{2}{*}{$\begin{array}{l}\text { Restorative } \\
\text { materials }\end{array}$} & \multirow{2}{*}{$\begin{array}{l}\text { No. of } \\
\text { samples }\end{array}$} & \multicolumn{4}{|c|}{ Microleakage scores } & \multirow{2}{*}{$\begin{array}{l}\text { Mean } \\
\text { score }\end{array}$} & \multirow[t]{2}{*}{$S D$} & \multirow[t]{2}{*}{ Mean score $\pm S D$} \\
\hline & & 0 & 1 & 2 & 3 & & & \\
\hline $\begin{array}{l}\text { Colored compomer } \\
\text { (group A) }\end{array}$ & 10 & 8 & 1 & - & 1 & 0.4 & 0.9661 & $(0.4 \pm 0.9661)$ \\
\hline $\begin{array}{l}\text { Ormocer } \\
\text { (group B) }\end{array}$ & 10 & 9 & 1 & - & - & 0.1 & 0.3162 & $(0.1 \pm 0.3162)$ \\
\hline $\begin{array}{l}\text { Giomer } \\
\text { (group C) }\end{array}$ & 10 & 3 & 5 & - & 2 & 1.1 & 1.1005 & $(1.1 \pm 1.1005)$ \\
\hline $\begin{array}{l}\text { RMGIC } \\
\text { (group D) }\end{array}$ & 10 & 6 & 2 & 1 & 1 & 0.7 & 1.0594 & $(0.7 \pm 1.0594)$ \\
\hline
\end{tabular}




\begin{tabular}{llll}
\multicolumn{3}{l}{ Table 2: Descriptive statistics of comparision of microleakage in different groups using two sample rank test (Mann-Whitney U-test) } \\
\hline Groups & $U$ & $p$ & Result \\
\hline Group A vs group B & $U=44.50$ & 0.684 & Microleakage score is higher in group A than group B \\
Group A vs group C & $U=26.50$ & 0.075 & $\begin{array}{l}\text { Microleakage score is higher in group C than group A } \\
\text { Group A vs group D }\end{array}$ \\
Group B vs group C & $U=40.50$ & 0.481 & Microleakage score is higher in group D than group A \\
Group B vs group D & $U=34.00$ & 0.019 & Microleakage score is significantly higher in group C than group B \\
Group C vs group D & $U=37.00$ & 0.247 & Microleakage score is higher in group D than group B
\end{tabular}

Standard $(0.05,9)=23.01$, standard $p<0.05=$ significant, $U<23=$ significant

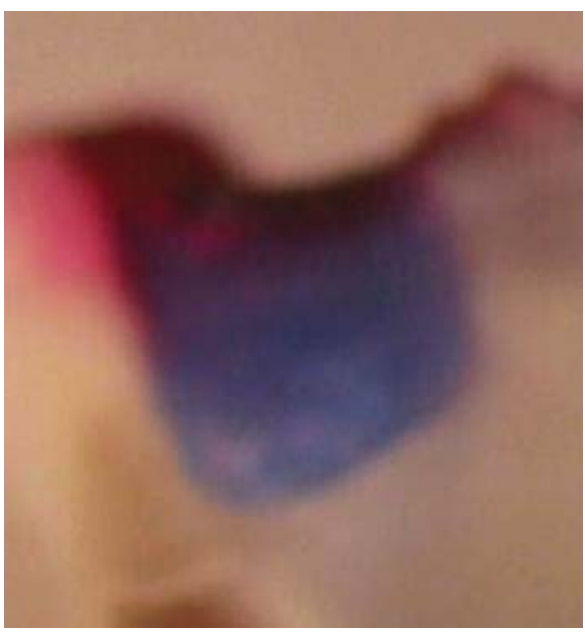

Fig. 8: Teeth with dye penetration (score 1) in colored compomer

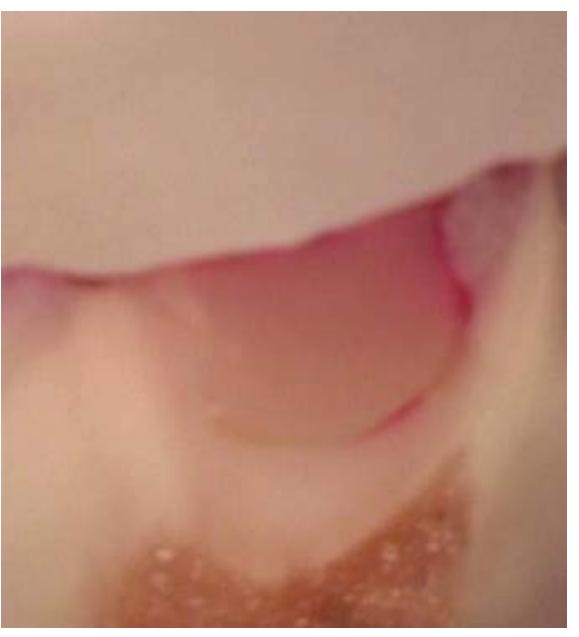

Fig. 9: Teeth with dye penetration (score 2) in RMGIC

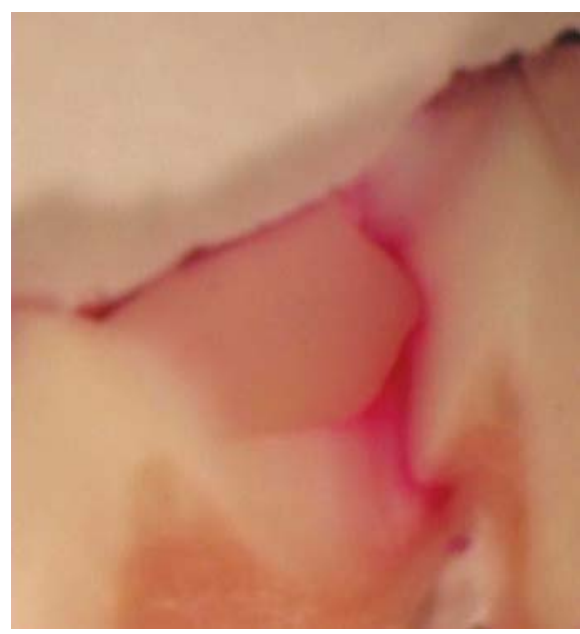

Fig. 10: Teeth with dye penetration (score 3) in giomer materials developed till date. In our study, we found that the least microleakage occurred around the ormocer group and the maximum microleakage was seen in giomer group. Microleakage observed in various groups can be summarized as: Group B (ormocer) < group A (colored compomer) $<$ group D (RMGIC) $<$ group C (giomer).

Our findings are in agreement with the findings of Yazici AR et al (2003) ${ }^{13}$ who studied the microleakage of class $\mathrm{V}$ cavities restored with three different types of flowable resin restorative material. They reported that ormocer was more effective than flowable composite and flowable compomer. The reason suggested for this was that ormocers have an inorganic backbone based on silicon dioxide and are functionalized with polymerizable organic units to produce three-dimensional compound polymer.

The probable reason for decreased microleakage in ormocer group may be due to its structure which is a biocompatible polysiloxane net with low shrinkage even prior to light curing. The inorganic network formation starts by hydrolysis and proceeds by polycondensation of $\mathrm{Si}(\mathrm{OR})_{3}$ groups. Starting with silane, polysiloxanes with polymersiable groups are formed. Ormocers are fully polymerized due to their preformed structure and their extremely high molecular weight, so they undergo considerably less shrinkage than composites or compomers. A possible explanation for the lower microleakage scores may be the three-dimensional structure and low modulus of elasticity which may have reduced polymerization shrinkage. ${ }^{13}$ Further, Hickel R et al $(1998)^{9}$ and Jain P et al $(2001)^{7}$ reported that reduced shrinkage, results in requiring less adhesion power of the adhesive and especially in the long run less marginal gap is expected.

Schirremeister JF et al (2004) ${ }^{14}$ reported that ormocer (Ceram X) was clinically effective in combination with prime and Bond XP as no recurrent caries was recorded and none of the restorations caused sensitivity after 6 months and the marginal integrity also remained grade A for 36 restorations out of 38. Similar result was seen in our study, in which using Prime and Bond XP, the marginal sealing ability of ormocer ranked higher than the other restorative materials.

In the present study compomer had comparatively decreased marginal leakage which is similar to the studies reported earlier by Morabito A et al (1997), ${ }^{11}$ Welbury RR et al (2000), ${ }^{15}$ Sikri V et al (2002). ${ }^{16}$ Mali P et al (2006) $)^{1}$ compared the microleakage of glass ionomer, composite 
resin and compomers. They concluded that microleakage was evident in all restorative materials, with glass ionomer showing maximum leakage followed by composite and compomers demonstrated the best results with minimum leakage. The results obtained in the study are similar to that of ours.

The leakage in compomer was less than RMGIC and giomer because of unique dual cure feature of colored compomer. Other compomers undergo resin polymerization only by light exposure. The two-component colored compomer is blended thoroughly while being injected through the mixing tip of the double-barreled syringe, thus initiating chemical polymerization. Self-curing gives assurance that material hardening will occur within 5 minutes throughout the resin mass, even if radiant energy from the light beam fails to penetrate completely. ${ }^{5}$

Contradictory results to our study have been reported earlier by Toledano et al (1999). ${ }^{17}$ They reported that microleakage was significantly higher with compomer when compared with resin-modified glass ionomer whereas Rodrigus JA et al (1999) ${ }^{18}$ stated that microleakage patterns of composite were similar to that of the compomers. Bracket et al (1998) $)^{19}$ concluded that there was no significant difference in microleakage between two lightcured glass ionomer restorative materials and a compomer, this differed from the conclusion we found in our study as in our study there was a slight significant difference between the two groups.

In our study RMGIC had greater microleakage score than ormocer and compomer which could be due to the immediate finishing/polishing procedure which was employed in our study according to the manufacturer's instructions. It has been reported by Yap AUJ et al (2002) ${ }^{20}$ that in addition to surface roughness, immediate finishing/ polishing could compromise the marginal seal of RMGIC to tooth. Although immediate finishing/polishing did not effect the marginal seal to dentin, it increased microleakage at enamel margins. ${ }^{20}$ Similar conclusions were drawn by Irie and Suzuki $1999^{21}$ and 2002. ${ }^{22}$

In our study the microleakage score of the giomer restorative material is the highest thereby suggesting the other three materials to be better than giomer with regards to the marginal integrity. Since, there were several steps involved in our study like storage, thermocycling, manipulation, dye penetration, etc. so the result can be due to any variation in any of the above procedures. As giomer is a new material and not much of studies have been done on it, so more work is needed to be done to have a better opinion of this new material. In in vitro studies, as ours, the teeth were not subjected to mechanical stress, occlusal wear and other biological factors. Hence, long-term stability of the restorative material in vivo and marginal sealing ability of such restorations should be investigated in order to have a better option for restorations in primary molars.

Although the results obtained from the present study may not be correlated to clinical situations, nevertheless they provide some useful information regarding these latest restorative materials.

\section{SUMMARY AND CONCLUSION}

The following conclusions can be drawn from the present study:

1. The marginal sealing ability of ormocer was found highest among all the dental restorative materials used in the study. The giomer restorative material expressed the lowest marginal sealing ability.

2. The microleakage scores of colored compomer, ormocer, giomer and RMGIC can be summarized as:

Ormocer $<$ colored compomer $<$ resin modified glass ionomer cement $<$ giomer.

\section{REFERENCES}

1. Mali P (Department of Pedodontics and Preventive Dentistry, K.L.E.S.'s Institute of Dental Sciences, Belgaum, Karnataka, India), Deshpande S, Singh A. Microleakage of restorative materials: an in vitro study. J Indian Soc Pedod Prev Dent 2006 Mar;24(1):15-18.

2. Kidd EA. Microleakage in relation to amalgam and composite restorations: A laboratory study. Br Dent J 1976 Nov 16;141 (10):305-310.

3. Mount GJ (University of Adelaide, Australia). Glass ionomer cements and future research. Am J Dent 1994 Oct;7(5):286292.

4. Burke FJ (University of Birmingham School of Dentistry), Fleming GJ, Owen FJ, Watson DJ. Materials for restoration of primary teeth: Glass ionomer derivatives and compomers. Dent Update 2002 Jan-Feb;29(1):10-14, 16-17.

5. Croll TP (Department of Pediatric Dentistry, University of Pennsylvania School of Dental Medicine, Philadelphia, Pennsylvania, USA). MagicFil: A colorful kiddie compomer. Compend Contin Educ Dent 2002 Nov;23(11):1044-1046, 1048.

6. Croll TP (Department of Pediatric Dentistry, University of Pennsylvania School of Dental Medicine, Philadelphia, PA, USA. willipus@tradenet.net), Helpin ML, Donly KJ. Multicolored dual-cured compomer. Pediatr Dent 2004 MayJun;26(3):273-276.

7. Jain P. Ormocer-biocompatible, replacement for amalgam, composite and compomers. Journal of Conservative Dentistry 2001;4(2):79-83.

8. Kugel G, Garcia-Godoy F. Direct and indirect esthetic adhesive restorative materials: A review dental news-Articles Predictal.htm.

9. Hickel R, Dasch W, Janda R, Tyas M, Anusavice K. New direct restorative materials. FDI Comission Product. Int Dent J 1998 Feb;48(1):3-16.

10. Prabhakar AR (Department of Pedodontics and Preventive Dentistry, Bapuji Dental College and Hospital, Davangere, 
Karnataka), Madan M, Raju OS. The marginal seal of a flowable composite, an injectable resin modified glass ionomer and a compomer in primary molars: An in vitro study. J Indian Soc Pedod Prev Dent 2003 Jun;21(2):45-48.

11. Morabito A (Department of Pedodontics, University of Torino, Italy), Defabianis P. The marginal seal of various restorative materials in primary molars. J Clin Pediatr Dent 1997 Fall; 22(1):51-54.

12. Gladys S, Van MB, Lambrechts P, Vanherle G. Microleakage of adhesive restorative materials. American Journal of Dentistry 2001;14(3):170-176.

13. Yazici AR (Hacettepe University, Faculty of Dentistry, Department of Conservative Dentistry, Ankara, Turkey. ruyay@hacettepe.edu.tr), Ozgunaltay G, Dayangac B. The effect of different types of flowable restorative resins on microleakage of Class v cavities. Oper Dent 2003 Nov-Dec;28(6):773-778.

14. Schirrmeister JF, Huber K, Hellwig E, Hahn P. Six months evaluation of the new ormocer restorative 'Ceram $\mathrm{X}$ '.

15. Welbury RR (Department of Child Dental Health, Dental Hospital and School, Newcastle upon Tyne. R.R.Welbury @ncl.ac.uk), Shaw AJ, Murray JJ, Gordon PH, McCabe JF. Clinical evaluation of paired compomer and glass ionomer restorations in primary molars: Final results after 42 months. Br Dent J 2000;189(2):93-97.

16. Sikri V, Singh H. A comparative evaluation of light cure composites, light cure glass ionomers and compomers for restoration of cervical abrasion erosion lesions-An in vivo and in vitro study. Journal of Conservative Dentistry 2002;5(1):2231.

17. Toledano M (University of Granada, Granada, Spain), Osorio E, Osorio R, Garcia-Godoy F. Microleakage of class V resinmodified glass ionomer and compomer restorations. J Prosthet Dent 1999 May;81(5):610-615.

18. Rodrigues JA (Departamento de Odontologia Restauradora, Faculdade de Odontologia de Piracicaba-UNICAMP, SP, Brazil), De Magalhães CS, Serra MC, Rodrigues Júnior AL. In vivo microleakage of glass-ionomer composite resin hybrid materials. Oper Dent 1999 Mar-Apr;24(2):89-95.

19. Brackett WW (Department of General Dentistry, College of Dentistry, University of Tennessee-Memphis, USA), Gunnin TD, Gilpatrick RO, Browning WD. Microleakage of class V compomer and light cured glass ionomer restorations. J Prosthet Dent 1998 Mar;79(3):261-263.

20. Yap AU (Department of Restorative Dentistry, Faculty of Dentistry, National University of Singapore, Republic of Singapore), Mok BY. Surface finish of a new hybrid aesthetic restorative material. Oper Dent 2002 Mar-Apr;27(2):161-166.

21. Irie M (Department of Biomaterials, Okayama University Graduate School of Medicine and Dentistry, Japan), Suzuki K. Effects of delayed polishing on gap formation of cervical restorations. Oper Dent 2002 Jan-Feb;27(1):59-65.

22. Irie M (Okayama University Dental School, Department of Biomaterials, Japan), Suzuki K. Water storage effect on the marginal seal of resin modified glass ionomer restorations. Oper Dent 1999 Sep-Oct;24(5):272-278.

\section{ABOUT THE AUTHORS}

\section{Gunjan Yadav (Corresponding Author)}

Senior Lecturer, Department of Pedodontics, Sardar Patel Post Graduate Institute of Dental and Medical Sciences, Lucknow, Uttar Pradesh, India, e-mail: gunjanyadav@rediffmail.com

\section{Usha Rehani}

Ex-Professor and Head, Department of Pedodontics and Preventive Dentistry, Subharti Dental College, Meerut, Uttar Pradesh, India

\section{Vivek Rana}

Associate Professor, Department of Pedodontics and Preventive Dentistry, Subharti Dental College, Meerut, Uttar Pradesh, India 